Nuclear Physics B (Proc. Suppl.) 210-211 (2011) January/February 2011

\title{
BEACH 2010
}

Proceedings of the 9th International Conference on Beauty, Charm and Hyperons in Hadronic Interactions

Università di Perugia

Perugia, Italy

21-26 June 2010

Editor-in-chief:

M. Bozzo

Editors:

P. Cenci

G. Anzivino

M. Biasini

C. Cecchi

J. Mc Kenna

A. Nappi

M. Pepe

N. Solomey

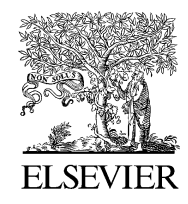

Amsterdam - Boston - London - New York - Oxford - Paris - Philadelphia - San Diego - St. Louis 